\title{
ASSERTIVIDADE DE PESO EM CARREGAMENTOS VOLUMÉTRICOS DE VAGÕES: UMA APLICAÇÃO NA MINERAÇÃO DE FERRO*
}

\section{Resumo}

\author{
Carlos Cristiano Carvalho Teixeira ${ }^{1}$ \\ Vicente de Paulo Amancio $^{2}$ \\ Wallace Costa Carvalho ${ }^{3}$ \\ Wendelling Átila Correia de Andrade ${ }^{4}$ \\ Emerson Klippe ${ }^{5}$ \\ Pedro Henrique Librelon de Faria ${ }^{6}$ \\ Herbert Ricardo Garcia Viana ${ }^{7}$
}

No carregamento volumétrico de vagões, onde a variância de pesos carregados é relevante, ocorrem grandes limitações operacionais, que vão desde a percepção do volume em carregamento até a capacidade real de controle. Neste contexto, a diversidade de cenários é enorme: velocidades variadas (25\% a $80 \%$ da capacidade), variação do minério, diferentes tipos de vagões, etc. Maximizar ou atingir o ponto ótimo com repetibilidade leva tempo e experiência. A solução considerou a aplicação intensa e avançada de instrumentação e recursos de automação, obtendo um resultado favorável de elevação da capacidade de controle sobre o peso em carregamento, nas diversas condições operacionais. A metodologia utilizada partiu de uma engenharia conceitual destacando 0 tratamento de riscos considerando as imprecisões e as técnicas avançadas de controle necessárias. Instrumentos e equipamentos também foram tratados dentro desses riscos, entre eles: balanças, radares 2D, identificação dos tipos de vagões, níveis dos silos, lasers para medições de precisão e para redundâncias, e ainda a simulação para testes do processo. Conclusão: 1. Maior capacidade de controle de peso carregado e menor variabilidade. 2. A imprevisibilidade na variação do material como desafio adicional para os automatismos. 3. Simuladores como diferencial na implantação da solução.

Palavras-chaves: Silo; Carregamento volumétrico; Automático; Vagão.

\section{Abstract}

\section{GETTING ASSERTIVENESS BY WEIGHT WITH VOLUME LOADINGS}

At the railcar's volumetric loading, where the loaded weight variance is relevant, occur significant operational limitations, ranging from the perception of volume until the actual capacity of control. In this context the variety of scenarios is huge: different load speeds ( $25 \%$ to $80 \%$ of capacity), ore variation, different railcars, etc. Maximize or achieve the optimum point with repeatability takes time and experience. The solution considered the application of intense and advanced instrumentation and automation resources getting a favorable result by lifting the control capacity over the weight loaded under different conditions. The methodology began from a conceptual engineering emphasizing the risks treatment considering the inaccuracies and advanced control techniques necessary to achieve the goal. Besides the advanced techniques, the solution involved the installation of: additional railroad scales, 2D radars, instruments to identify different railcars and silo levels, lasers for precision measurements and redundancies and application of simulation for tests. Conclusion: 1. Loading by volume aiming weight with less variability and additional load per railcar. 2 . The unpredictability on the material variation creating difficulties in automation. 3. Simulators as a differential to implementation the solution.

Keywords: Silo; Volumetric loading; Automatic; Railcars.

\footnotetext{
Técnico Automação, Gerente Accenture, Belo Horizonte, MG, Brasil.

Engenheiro Automação, MBA Gestão Empresarial, Ger. Sênior Accenture, Belo Horizonte, MG, Brasil.

Engenheiro de Automação - Gerente Accenture, Belo Horizonte, MG, Brasil.

Engenheiro Eletricista, MBA Gestão Empresarial, PMP, Ger. Sênior Accenture, Belo Horizonte, MG, Brasil.

Supervisor de Automação, Vale, Carajás, Pará, Brasil.

Gerente de Área, Vale, Carajás, Pará, Brasil.

Gerente Executivo de Tratamento de Minério, Vale, Carajás, Pará, Brasil.
} 


\section{INTRODUÇÃOO}

O processo de carregamento ferroviário, apesar de uma concepção simples, mas robusta, exige alta precisão de controles, especialmente por razões de segurança, e também pelo grau de dificuldade de controle. Num cenário onde a previsibilidade do material é nula ou limitada, o grau de dificuldade se eleva ainda mais. Diversas características precisam ser consideradas, como: fluidez, umidade, agressividade da área, disponibilidade, demandas e capacidades pulmão, taxa de amostragem e precisão. $\mathrm{Na}$ aplicação de técnicas de medição para controles volumétricos, onde a média de peso carregado é determinante para o negócio, temos um cenário ainda mais crítico. Nestes casos, estimar e controlar pesos assertivos com medições volumétricas, tanto na variabilidade positiva quanto na negativa, é o negócio, mas também é o desafio.

\section{VARIÁVEIS DE PROCESSO E CONDIÇÕES OPERACIONAIS}

As diversas características, tanto do material como do processo, apresentam impactos no grau de dificuldade na capacidade de controle do processo. Ressaltamos dois critérios de capacidade de controle impactados: a assertividade na estimativa de peso e a capacidade de descarga controlada.

\subsection{Características do Minério}

Diversas características do minério interferem na capacidade de controle e na assertividade de peso, ressaltamos aqui: a fluidez, a umidade e a densidade.

A característica de fluidez do material apresenta uma grande gama de comportamentos, chegando a ultrapassar 10 vezes a fluidez de um material a outro, e apresenta ainda variações durante a descarga do silo. Junto com a fluidez podese observar também a variação da umidade, além de outras características.

A densidade do material apresenta variações naturais significativas, mas essa variação é muito acentuada ao se agregar as outras características do material em carregamento. Neste cenário, as variações de densidade se tornam o limitador base para o processo na assertividade da estimativa de peso, uma vez que a variação da densidade está diretamente associada.

A própria diversidade de características de materiais também interfere sobre 0 critério de capacidade de controle. O sistema precisa atuar diferentemente na medida da mudança do comportamento do material, na necessidade de cada região do vagão e na dinâmica do cenário operacional (velocidade, taxa, distribuição, etc.).

\subsection{Características do Processo}

Diversas características do processo interferem na capacidade de controle, entre elas: a velocidade das comportas, a velocidade de operação, o balanço de carga no vagão e entre comportas, o tipo de vagão, os instrumentos em operação e o risco meta sobre o ritmo.

O material descarregado estará em queda livre, e isto sobre uma demanda de grandes vazões. As comportas e as unidades hidráulicas, precisam ter sua capacidade e repetibilidade certificadas para que atendam às demandas 
circunstanciais do processo, em especial as que impactam na assertividade de peso.

A velocidade dos vagões para a operação de carregamento pode apresentar grande variação ou diversidade de patamares. Os patamares de velocidade de operação de carregamento interferem tanto na assertividade do peso como na capacidade de controle de descarga. Quanto maior a velocidade, maior a dificuldade. Sobre a assertividade, o impacto se deve à rotina operacional ter menos tempo para identificar o comportamento e disposição do material. Sobre a capacidade de controle de descarga, o impacto se deve à elevação de vazão de trabalho e o menor tempo para atuação em cada região do vagão.

As operações das comportas ocorrem, em boa parte do tempo, sucessiva e simultaneamente, o que eleva o grau de atenção operacional e reduz o tempo de ação para atuação nos desvios. A ação simultânea traz ainda uma preocupação a mais com a capacidade hidráulica do sistema, de atender à movimentação simultânea das comportas.

Os diversos tipos de vagões também interferem nas capacidades do sistema. As diversas características desses trazem diferenças que interferem: no cálculo do volume, na percepção de velocidade, na aferição de posição, entre outros. As molas dos vagões também impactam sobre a assertividade de peso, uma vez que sua flexão gradativa, mas variável no decorrer do carregamento, muda as referências de altura volumétrica, uma vez que o fundo do vagão muda de altura.

Pela necessidade de avançada instrumentação e em quantidade, o risco sobre a instrumentação se eleva e para manter o processo o mais disponível, a flexibilidade operacional precisa ser trabalhada. É importante possibilitar combinações operacionais conforme os instrumentos disponíveis. Como exemplo entre diversos, uma deficiência ou ausência de pesagem de tara não necessita interferir na disponibilidade do sistema, apesar de certamente reduzir sua capacidade.

Conforme o planejamento de produção, o risco sobre a sobrecarga pode ser tratado como variável, o que altera a assertividade esperada no peso por vagão, e consequentemente, a meta de peso estabelecida para o cenário.

As projeções de materiais sobre a estrutura do silo são também impactantes, pois influenciam na disponibilidade do sistema, pela interferência e contaminação dos instrumentos. A região dos silos de carregamento é tipicamente uma área de alta contaminação e umidade. Para as balanças ferroviárias, é preciso atenção especial à estabilidade e boa condição de instalação, mas estas ainda precisam estar preparadas para atuar nesse cenário adverso.

\subsection{Capacidade Pulmão e Variação de Taxa}

A capacidade dos silos de carregamento determina o critério de ritmo de produção, pois um excesso de carga nesses provocaria a quebra do ritmo, por interromper a alimentação, mas a falta também pode ser indesejada, pois indicaria uma operação em ritmo maior que o necessário com consequente impacto na assertividade. $\mathrm{Na}$ existência de sequenciamento de silos, estes também poderiam ser elemento de balanço de carga, com ótica na maximização operacional por assertividade, mas neste caso aparece ainda um novo critério, de tempo de produção, uma vez que os silos sequenciados possuem cada qual sua capacidade de abastecimento. Em todos estes casos, a precisão necessária para o peso no vagão será o critério principal delimitador do balanço de demanda possível. 


\section{OBJETIVOS}

\subsection{Estimativa Assertiva de Peso}

A assertividade na estimativa do peso é predecessora dos diversos critérios finais para operação e produção no processo de carregamento de vagões. Assim sendo, conforme a assertividade atingida, pode-se maximizar os resultados buscando explorar a capacidade operacional dos equipamentos.

A assertividade tem alguns critérios base que precisam ser considerados para determinar uma solução, por se tratar de condições que podem interferir na assertividade, entre elas estão: características e variabilidade do material, velocidade de carregamento, tipo de vagão, experiência operacional e eficiência dos equipamentos, e ainda o risco assumido.

Considerando esse cenário, a assertividade pode ser expressa por uma medida dinâmica de desvio padrão do peso e, aplicando regras estatísticas, o sistema poderá dispor de informações para estabelecer uma meta segura, ou com os riscos estimados e assumidos, de forma a atender os critérios de produção desejados.

Nos critérios de produção que demandam a assertividade podemos observar:

- O peso transportado nos vagões tem impacto direto na capacidade de produção e na eficiência logística. Na logística de transporte, os custos principais não se alteram com a mudança na média transportada, com isto, a elevação da média representa ganho significativo na eficiência, sendo que na logística de transporte estão grandes custos da cadeia do negócio.

- O principal critério para estabelecer a capacidade de elevação da média é o limite de peso, o qual pode ser determinado pelo vagão ou pela ferrovia. Os eventuais excessos precisarão ser retirados e devem ser evitados, pois influencia ainda no ritmo de produção e na capacidade de planejamento de produção.

\subsection{Operações Automáticas e Diversidade Operacional}

À medida que se aproxima do limite de peso, a precisão exigida se eleva. Essa precisão passa a ser crítica para as operações manuais. A operação automática pode atingir a precisão e a repetibilidade nas diversas condições operacionais e possibilita a flexibilização de possibilidades operacionais e disponibiliza a atenção humana a outros critérios de operação e produção, possibilitando inclusive a eficiência e a maximização operacional.

Algumas características do processo também intensificam o benefício da operação automática, como o tempo para disponibilidade de dados. O tempo variável, o pouco tempo ou a ausência de tempo para decisões reduzem a eficiência operacional manual.

Outro critério determinante para a aplicação do automático é a necessidade da ampliação de elementos do controle de processo. A aplicação de operação automática evita a ampliação dos recursos humanos na mesma proporção da ampliação dos elementos de controle e possibilita que uma mudança na rotina operacional seja o suficiente para que o mesmo recurso mantenha o processo. 


\section{ENGENHARIA CONCEITUAL}

A aplicação da engenharia conceitual nesse cenário é decisiva para a viabilidade e o direcionamento eficiente das ações de viabilização. A viabilidade está associada a várias ações específicas e precisas, sem a qual o resultado não seria obtido. $O$ mapeamento do estado atual, dos objetivos, das ações possíveis, dos seus riscos e do plano de ação, permitiu atingir o limiar necessário para o resultado, o qual se tratava de um desafio com intensa aplicação de técnicas inovadoras. O foco dos riscos sobre o objetivo é outra marca importante para o resultado desejado.

É importante observar que a maioria dos riscos mapeados atingiram níveis de ações avançadas, devido à alta frequência de ocorrência e sinalização dos mesmos, o que provocou, durante todo o desenvolvimento, o replanejamento das ações e comunicações na matriz $\mathrm{RACl}$, ressaltando a validade e qualidade do mapeamento de risco.

$\mathrm{Na}$ avaliação de viabilidade, focando na assertividade de peso entre outros critérios, alguns elementos foram mais marcantes:

- Balança ferroviária - disponibilidade física e lógica, precisão, funcionalidades e tempo de resposta;

- Desempenho das comportas - velocidade, simultaneidade e repetibilidade, ciclo de comando e precisão de posicionamento, disponibilidade, unidades hidráulicas e capacidade energética instalada;

- Medições volumétricas por sessão do vagão;

- Mapeamento dinâmico de volume por sessão do vagão;

- Elementos de aferição de posição;

- Redundância;

- Sustentabilidade operacional;

- Precisão e desvio padrão.

- E ainda outros critérios possíveis, como: balanço de descarga por comportas sucessivas, balanço de carga por pátio, disponibilidade física de máquinas, capacidades de abastecimento e operação simultânea de linhas;

\section{PROCESSO}

\subsection{Processo Original}

A rotina operacional original constava da utilização de duas comportas operadas manualmente por um único operador. A aplicação das balanças ferroviárias se destinava à computação de peso final e à realimentação visual para correção do volume para a meta de peso médio projetado. O risco de sobrecarga era avaliado pela aproximação ou pela incidência, eventualmente promovendo a revisão da meta de peso para baixo, sobreposta pela meta de ritmo e número de sobrecargas.

Conforme o planejamento de produção, a velocidade de produção era determinada entre $25 \%$ a $80 \%$ da capacidade de projeto. A velocidade ainda apresentava grande variação por outros fatores do processo. À medida que se eleva a velocidade, elevase também o risco de sobrecarga e, consequentemente, acompanhava redução da meta de peso para controle do risco, ou a penalidade da redução do ritmo por sobrecargas. Esse mesmo cenário se repete quando da diversidade de materiais alimentados, uma vez que reduzem a capacidade de controle da descarga. 
O perfil pluviométrico do ano operacional e as características da lavra no mesmo período também acabam por influenciar os resultados, uma vez que nos anos com maiores índices pluviométricos, o material tende a criar maior dificuldade operacional, pelas mesmas características apresentadas acima. Desta forma, a média de peso carregado acompanha o índice pluviomético na proporção inversa. As médias nos últimos anos tinham apresentado crescimentos, e estiveram entre de $89 \%$ a $93 \%$ da capacidade.

\subsection{Novo Processo}

O novo processo de descarga agrega informações dinâmicas da carga e do material e cria novas interfaces de orientação para a meta. Além da dinâmica do peso estimado carregado, a meta e o perfil real do material ao longo do vagão podem ser acompanhados dinamicamente. Um sinaleiro externo orienta uma operação manual ou a avaliação do desempenho do controle, de forma a se atingir o peso e o balanceamento adequado da carga no vagão.
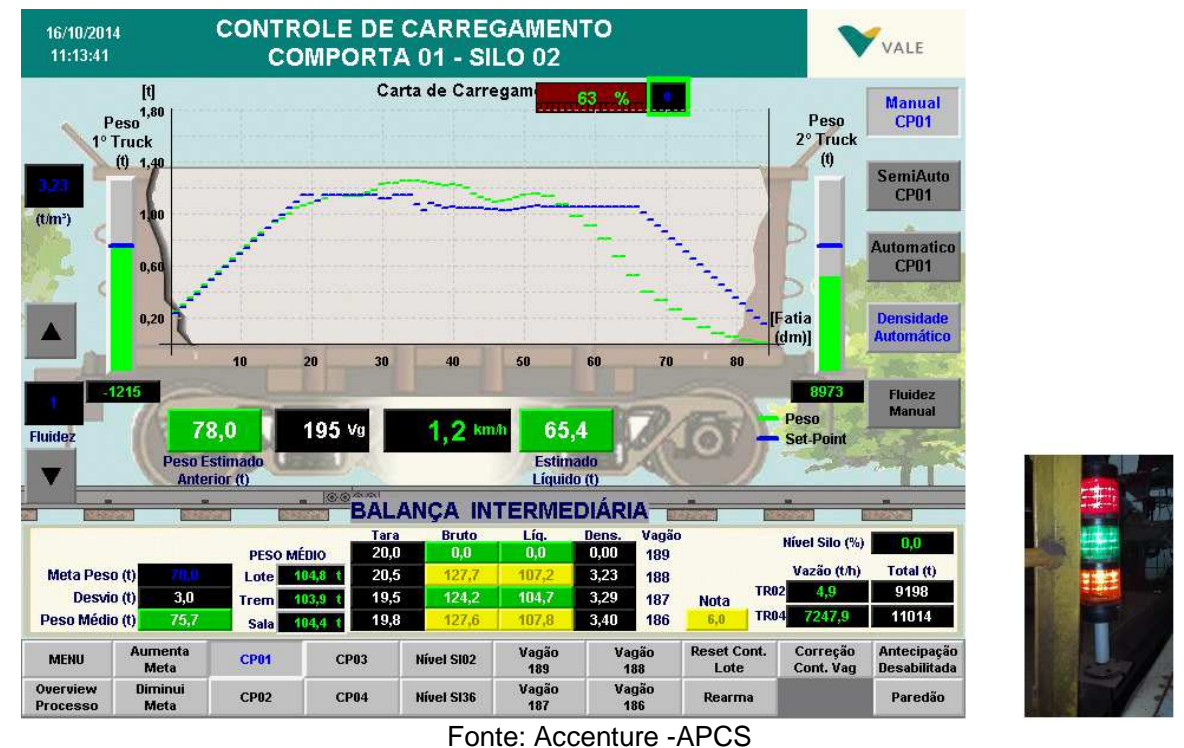

Figura 1. Abordagem de Implantação

A aplicação de pesagem ferroviária mais próxima do silo agilizou a realimentação do sistema.

As balanças ferroviárias passam a ter novas funções, entre elas, funções de controle. A balança de tara passa a ser usada para correção do peso meta, de forma a aproveitar ao máximo a capacidade de carga do vagão. A balança de saída do silo é utilizada para a pesagem do vagão realizado no silo e para cálculos de densidade e ajustes dos controles. A densidade recalculada automaticamente atualiza o peso estimado a partir dos volumes apurados, dinamicamente nos controles de descarga, elevando sua precisão. O risco de sobrecarga passa a ser controlado com mais efetividade e a meta de peso pode ser mantida, sem elevação do risco.

Mesmo considerando cenários de maior índice pluviométrico ou de características de lavra com maior variabilidade ou com características impactantes no sistema, o impacto no resultado passa a ser muito menor ou ignorado. Desta forma, a 
assertividade final tende a se manter estável, e consequentemente as metas de peso carregado podem a acompanhar.

O novo sistema dota a operação de grande capacidade de tracking de dados, o que traz redução significativa nos índices de tempo de diagnóstico e de retomada, o que se aplica também aos casos de sobrecarga.

\section{SISTEMA DE AUTOMAÇÃO}

A necessidade de estimativa dinâmica de peso cria diversas exigências de medição, cada qual com sua demanda de precisão. Cada uma dessas medições apresenta suas próprias características de dificuldade e variância de cenário.

As diversas medições consideradas foram:

- Medição de altura de material sob cada comporta;

- Medição de altura final na saída de cada comporta;

- Medição de altura final após silo;

- Medição dinâmica de posição e velocidade do vagão em cada ponto do processo;

- Identificação de características do vagão de cada posição no processo (dimensões e tipo);

- Posição de comportas;

- Contador de vagões;

- Identificação e dimensionamento de locomotiva;

Ainda outras medições e equipamentos viabilizam ou completam a exploração dos dados disponíveis;

- Nível dos silos;

- Unidades hidráulicas;

- Balanças.

\subsection{Instrumentação}

\subsubsection{Radar 2D - aplicação 3D}

Foi aplicada tecnologia radar para o mapeamento dinâmico dos volumes nos vagões em carregamento. A tecnologia é eficiente no cenário de agressividade, apresentando alta disponibilidade, o que não se conseguiu com outras tecnologias.

Diversas informações são extraídas a partir desse sistema, entre elas:

- Perfil volumétrico do vagão;

- Volume na sessão de saída;

- Altura do vagão;

- Ângulo de deposição do material.

O sistema envia dados de amostras dinâmicas e envia cada dado em intervalos máximos de 200ms e com precisão apurada para cada sessão.

As deficiências de precisão percebidas em algumas regiões e em momentos operacionais específicos foram tratadas com outros recursos paralelos, entre inferências e trenas pontuais de altura, onde foi viável.

As informações produzidas participam do controle de descarga e da medição do volume final por sessão para dispor a próxima fase de descarga. 


\section{$19^{\circ}$ Automação \& TI}
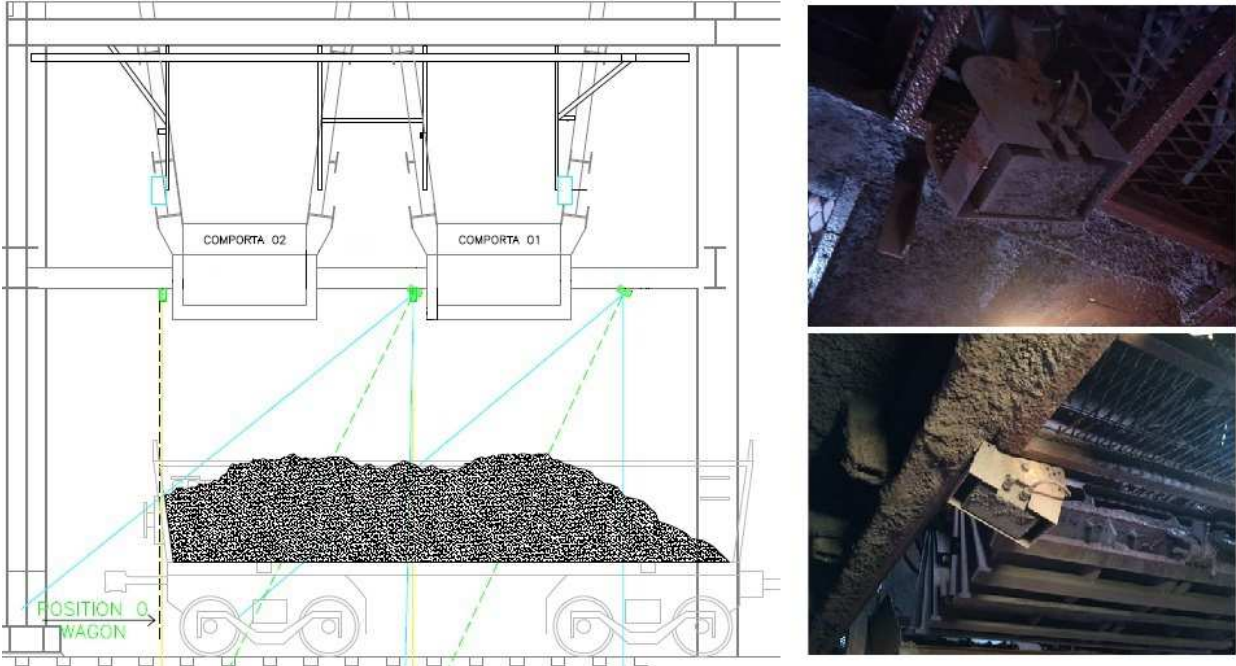

Fonte: Accenture -APCS

Figura 2. Medições radar - Altura dinâmica do material no vagão

\subsubsection{Medições óticas}

A aplicação de medições a laser teve amplo espectro. Em geral, a aplicação esteve associada à necessidade de precisão e velocidade de medição.

\subsubsection{Laser - nível no vagão}

As características de deposição do material nesse processo permitem a utilização de medições pontuais de altura do material para produzir um cálcullo final de volume médio por sessão e a precisão é adequada ao projetado para o processo. Na figura a seguir observamos uma medição de seção de material por três pontos, sendo um ponto no centro.

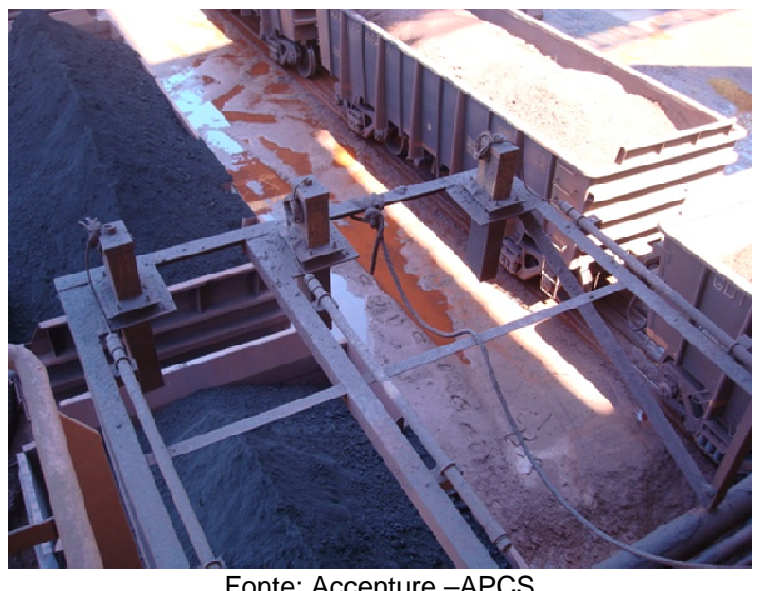

Figura 3. Medições Óticas - Nível do material no vagão

\subsubsection{Laser - posição/velocidade}

A monitoração do deslocamento do vagão e sua velocidade foram realizadas por um conjunto de trenas diagonais à lateral dos vagões, como pode ser observado na figura abaixo. A distribuição das trenas está associada a critérios de cobertura de zonas mortas na lateral do vagão e a cobertura de momentos operacionais do processo. 

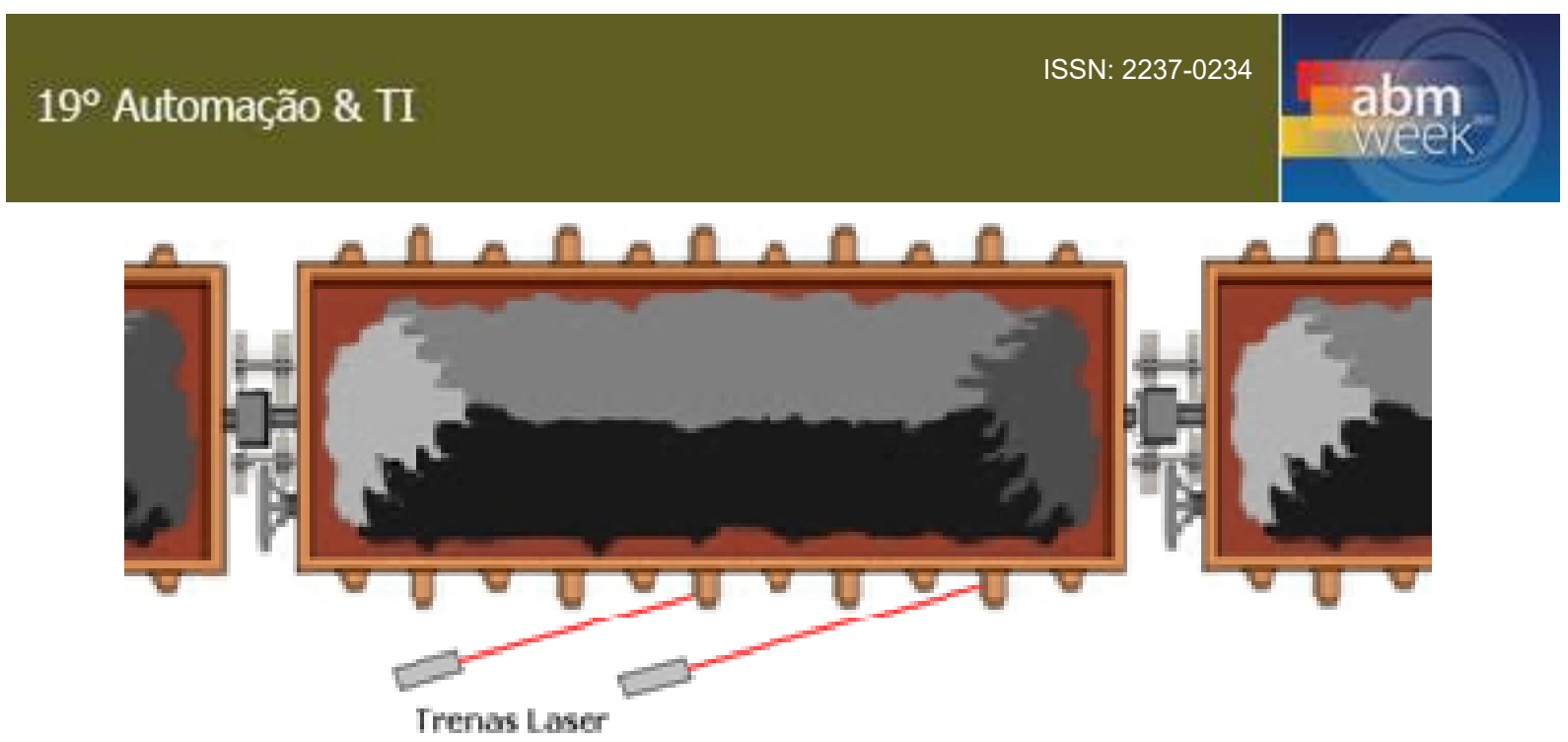

Fonte: Accenture -APCS

Figura 4. Posição/Velocidade - Posicionamento de trenas

A informação final de posição e velocidade é gerada em todas as fases do processo individualmente, de forma a se utilizar a máxima precisão do processo, e utilização de regras determinadas por software combinando as várias medições realizadas dinamicamente.

\subsubsection{Laser - contagem de vagões}

A contagem de vagões é realizada por um conjunto de trenas direcionadas para 0 fundo do vagão, como pode ser observado na figura abaixo. O mesmo recurso e utilizado para executar verificações de posição dos vagões na região de descarga das comportas.

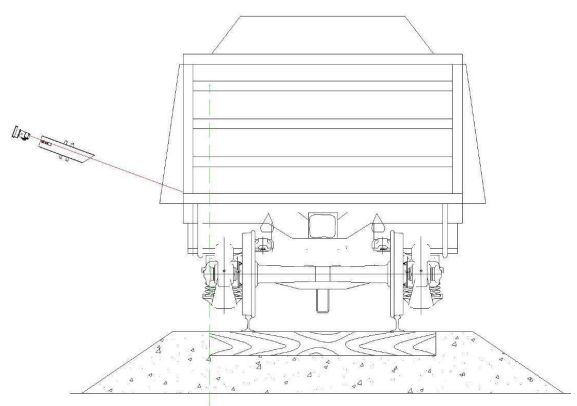

Fonte: Accenture -APCS

Figura 5. Contagem de vagões - Posicionamento de trenas

\subsubsection{Pesagem Ferroviária}

A pesagem ferroviária utiliza técnica de trilho instrumentado via strain gauge e trabalha com precisão projetada para $0,5 \%$ a $0,2 \%$ (6 a 9 grupos de células).

Devido ao cenário do local de instalação ser bastante adverso, os pesos passaram a ser tratados em seu valor total e também por eixo, de forma a tratar situações de falha sem reduzir a disponibilidade do sistema.

As balanças possuem classe de precisão elevada, mas o sistema viabiliza excelentes resultados mesmo quando estas trabalham com as precisões mínimas. A nova configuração de balanças, combinada com os novos recursos de tracking de dados, possibilitam um diagnóstico rápido das imprecisões ou falhas no sistema de pesagem, o que traz grande retorno para o melhor tempo em produção. 


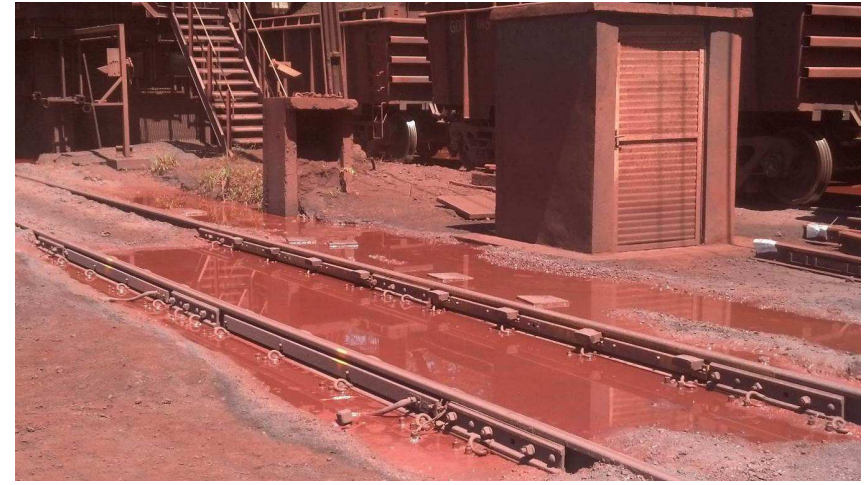

Figura 6. Pesagem ferroviária - Cenário de instalação

\subsubsection{Posição}

As posições das comportas são utilizadas no controle de posicionamento e são indispensáveis para a disponibilidade do sistema. A precisão de posicionamento é projetada para que o erro não ultrapasse a $5 \%$ e com ciclos de controle menores que $35 \mathrm{~ms}$. Devido ao grande risco sobre disponibilidade dos intrumentos na região, a posição trabalha com redundância de medição, sendo a medição primária feita com encoder (figura a seguir) e a secundária com trena.

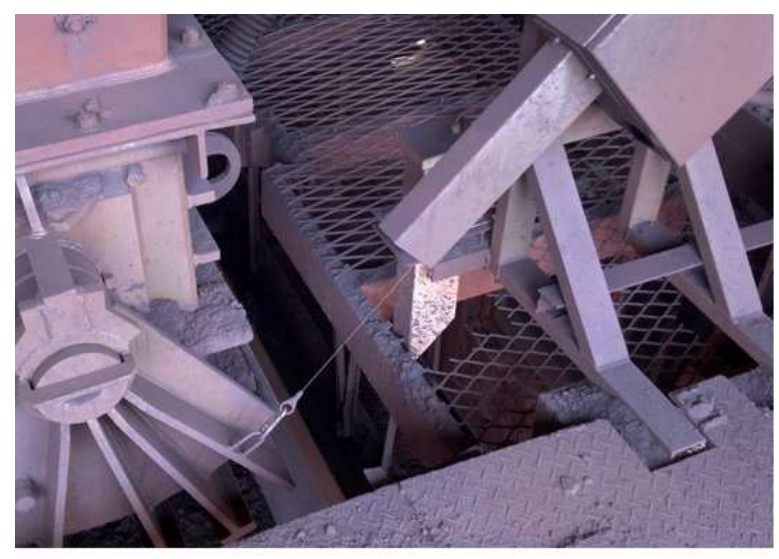

Posição do encoder no momento que a abertura percentual da comporta é de $0 \%$

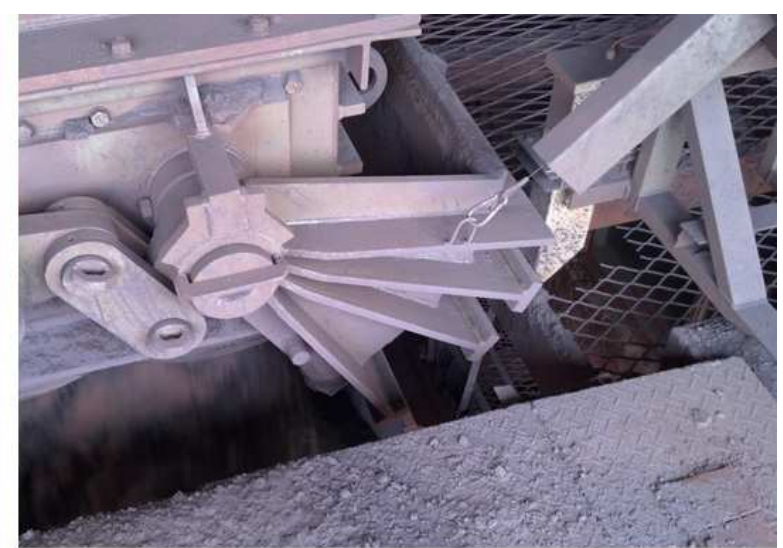

Posição do encoder no momento que a abertura percentual da comporta é de $100 \%$

Fonte: Accenture -APCS

Figura 7. Medição de Posição - Encoder de corda

\subsubsection{Nível de Silos}

A medição de nível dos silos possibilita a análise da demanda ideal de forma a buscar o balanceamento estável com o abastecimento. $\mathrm{Na}$ aplicação com diversos silos, auxilia a determinação da melhor distribuição de carga em cada ponto de descarga.

A tecnologia de medição radar possui bom desempenho, mas como em nossa aplicação ocorrem dois pontos de extração (duas comportas), precisamos monitorar o nível em dois pontos do silo. Nesta aplicação, utilizamos o trabalho combinado entre duas tecnologias, sendo uma radar e outra em ultrassom, uma vez que a segunda já era existente no sistema. Apesar da tecnologia ultrasom apresentar 


\section{$19^{\circ}$ Automação \& TI}

alguma deficiência nos níveis mais baixos, acabam por ser cobertas pela combinação dos radares.

Em nossa aplicação encontramos ainda um cenário de alimentação comum para duas linhas. Desta forma, os níveis são utilizados ainda para controle de distribuição e de demanda entre as linhas.

\subsubsection{Sistemas Hidráulicos e Capacidade Elétrica}

A operação das comportas avaliadas em seu desempenho indicou a necessidade de modificação da operação das unidades hidráulicas. Estas foram revisadas e modificadas para operação em nova rotina e novos ajustes, especialmente para atender ao alto fluxo hidráulico nas operações simultâneas das comportas.

Com a alteração da rotina das bombas, a demanda de energia elétrica foi alterada e o circuito de alimentação foi avaliado em capacidade e seletividade.

\subsection{SISTEMA DE CONTROLE}

A grande precisão necessária nas técnicas de medição e dos cálculos demandam elevados recursos de controle. A precisão da configuração se torna fundamental para o resultado, onde as tarefas e os dispositivos de entradas e saídas trabalham em taxas elevadas, de $5 \mathrm{~ms}, 17 \mathrm{~ms}$ e $60 \mathrm{~ms}$. As rotinas de menor prioridade trabalham em torno de $120 \mathrm{~ms}$.

As redes chão de fábrica fazem a interface com os instrumentos e processadores de sistema distribuídos na área garantindo o tempo agendado para cada instrumento, em sincronismo com as rotinas correspondentes.

A figura a seguir apresenta a configuração aplicada para a solução.

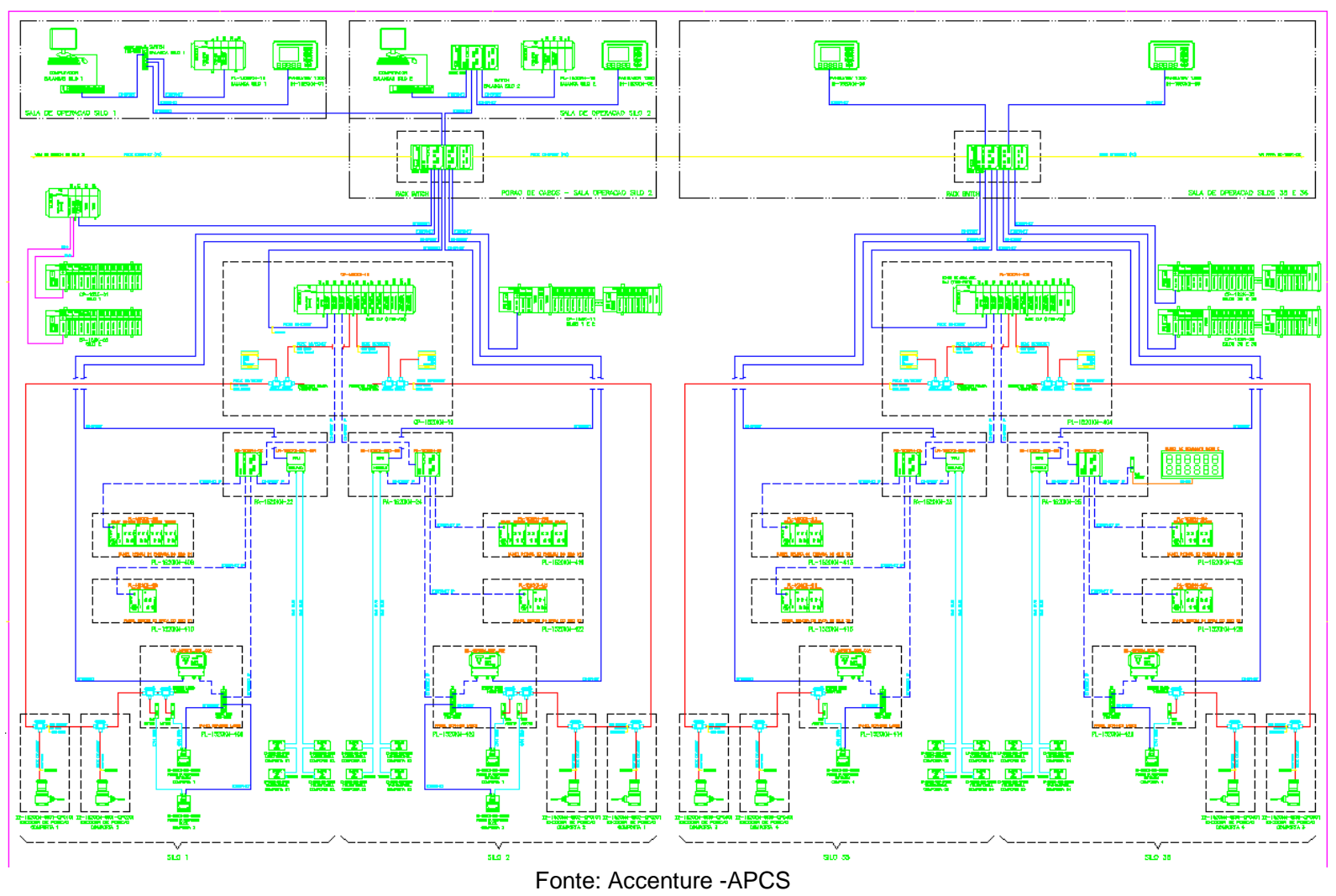

Figura 8. Configuração de sistema 


\subsection{Simulação de Processo}

A simulação de processo foi fundamental para o controle dos riscos e para a garantia dos resultados e da precisão. O mesmo sistema desenvolvido para os testes foi mantido e aplicado como um sistema de implantação e manutenção, que dava uma visão detalhada do sistema e do processo, contribuindo para a sustentabilidade do sistema. A figura a seguir apresenta uma visão de uma das telas, aplicada à visão geral do processo, com seus diversos elementos de monitoração, a qual vai além do foco apresentado neste trabalho, e apresenta um cenário total.

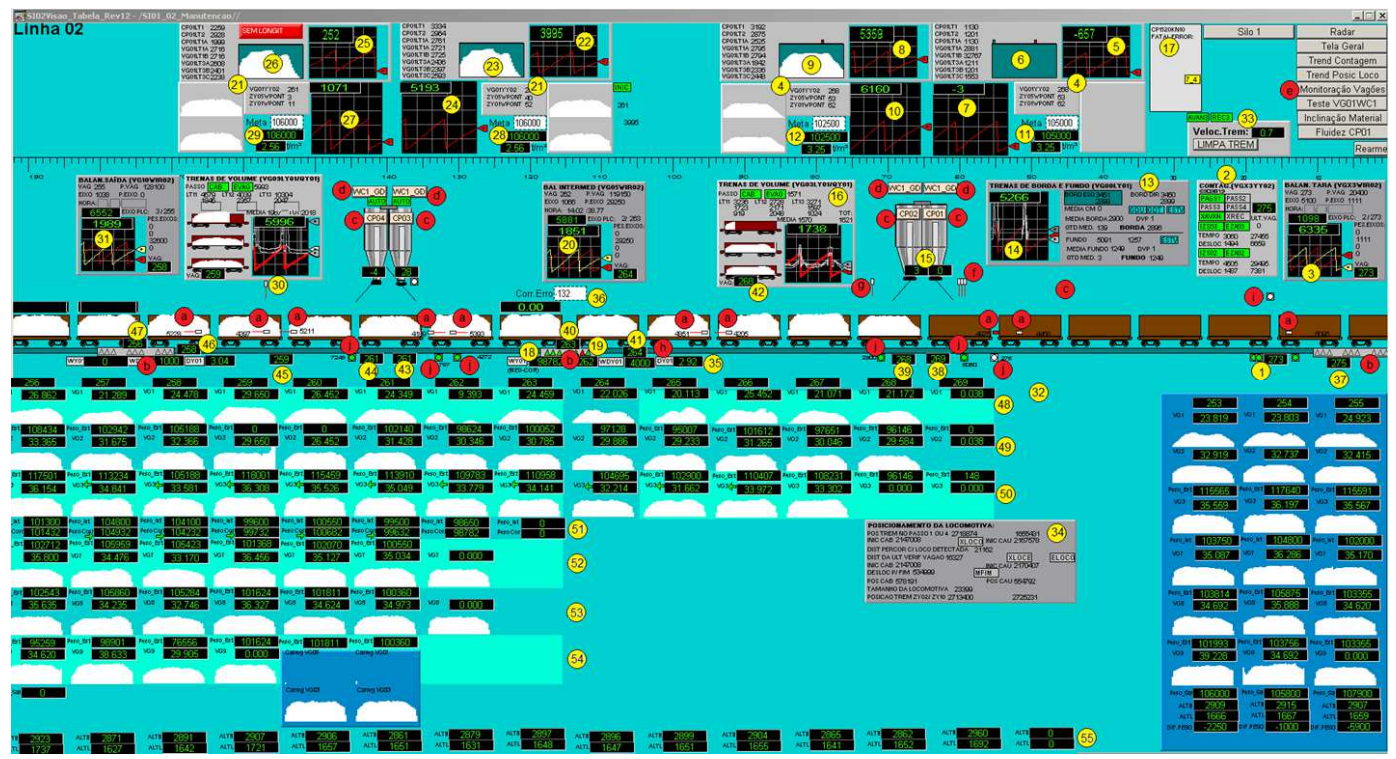

Fonte: Accenture -APCS

Figura 9. Sistema para simulação e manutenção

Um critério significativo é a utilização de desenvolvimentos abertos, que elevam a capacidade e a independência para a manutenção do sistema, fator este de grande risco em sistemas complexos.

O custo de desenvolvimento da simulação de processo é significativo em sistemas complexos, mas o impacto é ainda mais significativo. Foi necessária uma configuração específica para a simulação. A simulação foi desenvolvida em PLC e em sua base de dados foi registrado o comportamento operacional de cada instrumento. Para as simulações de deslocamento, foi criado um passo de simulação para cada $\mathrm{mm}$, o que demandou uma grande base de dados, inclusive pela quantidade de instrumentos. A alimentação da base dados foi feita a partir de amostras reais criadas pela aquisição de dados em outros instrumentos similares. Para os instrumentos sem similares, foi desenhado manualmente 0 seu comportamento no tempo e no espaço. Na figura a seguir observamos as características básicas da arquitetura de simulação. 

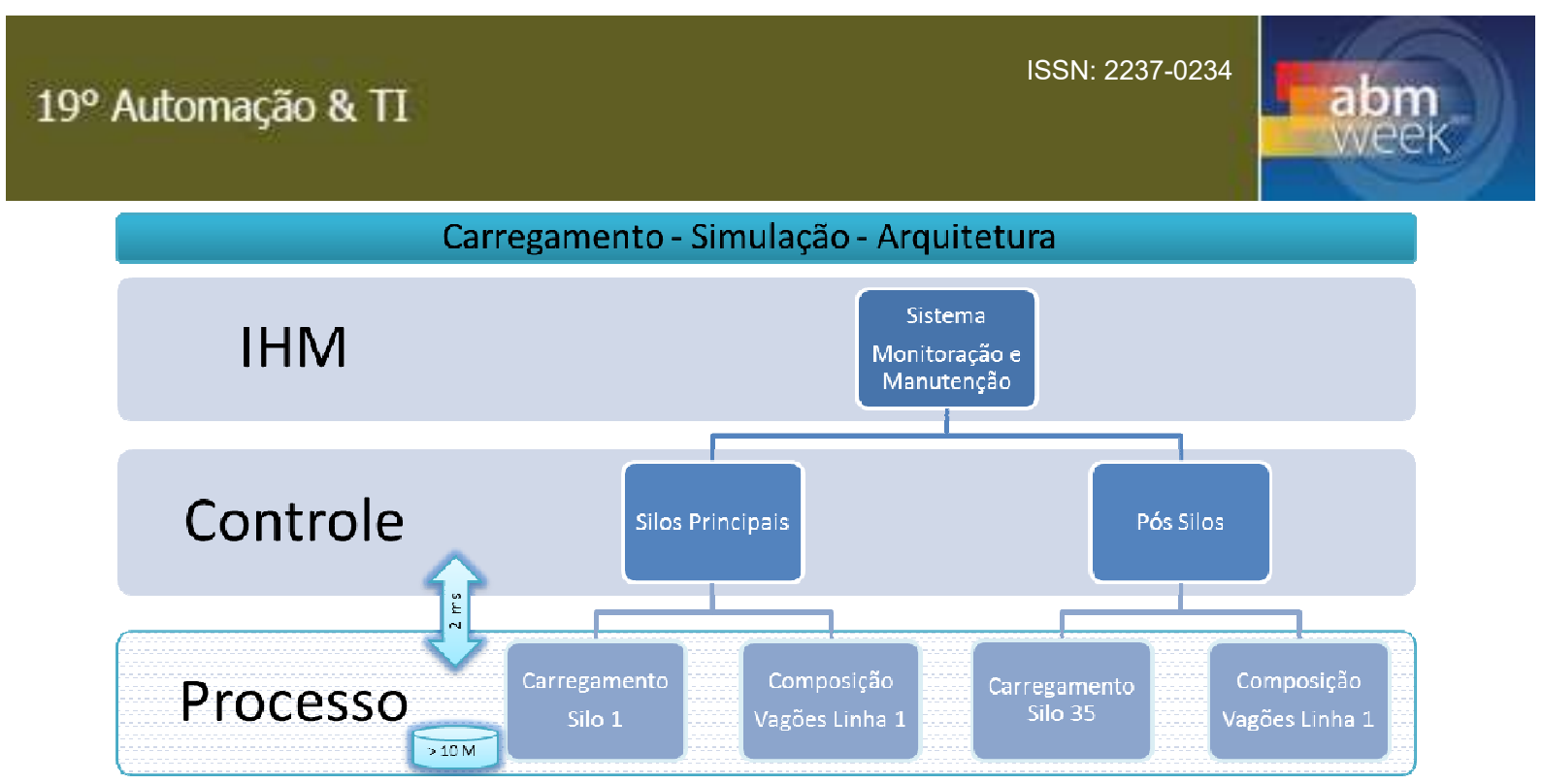

Fonte: Accenture -APCS

Figura 10. Configuração de simulação

\section{RESULTADOS}

Apesar dos resultados pontuais da estimativa de peso não terem sido comparados em histórico, o desvio padrão típico apresenta claramente o resultado. O desvio padrão típico da operação manual visual, isto é, por controle de nível visual do vagão, girava entre 3,5 e 2,2 t, e a operação manual com a estimativa de peso passa a operar com desvio entre 2,4 e 1,7 t.

Ocorre ainda outros critérios que apontam os resultados significativos, que são:

- o offset de realimentação, que passa de 12 para 5 vagões;

- disponibilidade do sistema;

- repetibilidade, redução de sobrecargas e tempo de carregamento.

Os resultados obtidos são muito diversificados um vez que a técnica foi amplamente utilizada no cenário, somando-se o resultado destas, em especial pela capacidade de tracking que o sistema fica dotado. No entanto, o resultado apresentado está restrito à aplicação da técnica em um único ponto.

\subsection{Principais Funcionalidades}

Diversas funcionalidades acompanharam os objetivos básicos e trazem grande contribuição para a rotina operacional e para os resultados de produção. Ressaltamos: tracking de material e de dados dos vagões, controle de demanda, posição e velocidade da composição, contador e rastreador de vagões e sinalização volumétrica para operação manual.

\section{CONCLUSÃO}

A aplicação de estimativa de pesos por medições de volume é plenamente viável e justificando inclusive grandes investimentos pelo seu retorno. Devido à técnica apresentar muitos fatores variantes, uma engenharia conceitual se torna fundamental, de forma que as precisões necessárias para o resultado, em cada funcionalidade, possam ser dimensionadas e a capacidade de cada técnica possa ser avaliada no cenário. 


\section{Automação \& TI}

A variação das características da matéria-prima pode ser grande limitador em soluções de controle volumétrico em carregamentos de vagões. Isto se deve à imprevisibilidade, o que pode exigir interferências manuais durante o processo de descarga. Para criar previsibilidade e melhorar esse cenário, ainda existem algumas hipóteses que podem ser consideradas, tanto sobre o comportamento do material durante a descarga, quanto no material ainda no silo, que não foram objeto deste trabalho.

A condição de grande número de instrumentação e de solução baseada em tracking de dados e de deslocamento, a precisão muito vinculada à técnica de instalação e de medição e as altas taxas de processamento, elevam o impacto de simuladores de processo para os testes. Apesar do grau de investimento, o retorno se mostrou muito significativo. 